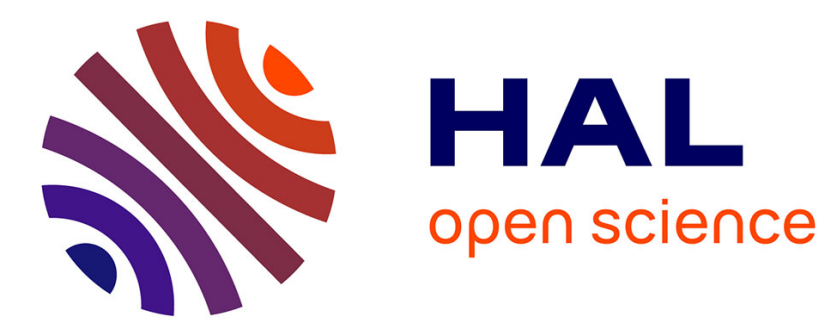

\title{
Damage and failure processes in structural materials
}

\author{
J. Embury
}

\section{To cite this version:}

J. Embury. Damage and failure processes in structural materials. Journal de Physique IV Proceedings, 1993, 03 (C7), pp.C7-607-C7-619. 10.1051/jp4:1993799 . jpa-00252219

\section{HAL Id: jpa-00252219 https://hal.science/jpa-00252219}

Submitted on 1 Jan 1993

HAL is a multi-disciplinary open access archive for the deposit and dissemination of scientific research documents, whether they are published or not. The documents may come from teaching and research institutions in France or abroad, or from public or private research centers.
L'archive ouverte pluridisciplinaire HAL, est destinée au dépôt et à la diffusion de documents scientifiques de niveau recherche, publiés ou non, émanant des établissements d'enseignement et de recherche français ou étrangers, des laboratoires publics ou privés. 
JOURNAL DE PHYSIQUE IV

Colloque C7, supplément au Journal de Physique III, Volume 3, novembre 1993

\title{
Damage and failure processes in structural materials
}

\section{J.D. EMBURY}

Department of Materials Science and Engineering, McMaster University, 1280 Main St. West, Hamilton, Ontario L8S 4L7, Canada

\begin{abstract}
At large plastic strains consideration must be given not only to the descriptions of work hardening and texture evolution but also to the process of damage accumulation and the documentation of the various modes of failure which may terminate the plastic history.

In tris presentation consideration is given first to documenting the various modes of failure and their dependence on stress state. It is then shown that damage accumulation can be studied in a quantitative manner by using model systems in conjunction with FEM calculations. Finally consideration is given to complex forming processes such as ironing to show how studies of damage initiation and accumulation relate to practical engineering problems.
\end{abstract}




\section{INTRODUCTION}

There are many examples both in service and in the processing of materials where the performance or fabricability of the material is limited by damage accumulation and fracture. This becomes of increasing importance as materials are used at higher stresses in service or fabricated at the limits of their formability. In addition the development of new materials such as metal matrix composites poses new problems because in many cases the scale and distribution of the reinforcing phase result in the development of microstructural damage at low plastic strains. Thus in these materials the process of damage accumulation must be incorporated into the constitutive laws for plastic flow in order to describe the strain history of the material as a function of the imposed stress state and temperature.

In order to describe a number of forming operations it is necessary to develop a quantitative description of large strain plasticity which includes damage accumulation. A variety of formalisms for the incorporation of damage mechanics into constitutive laws have been provided by the seminal work of Kachanov (1), Leckie (2) and LeMaitre (3). However it is also important to examine from a microstructural viewpoint the following processes a) classification of damage modes for various systems, b) the behaviour of model systems in order to elucidate the nature of the interaction of the reinforcing planes and the deforming matrix, c) the relationship of damage accumulation to practical deformation processes. The current work deals with a few selected aspects of these problems in order to provide a comprehensive overview. It must also be emphasized that in large strain deformation problems remain in other areas such as the understanding of the mechanisms of dynamic recovery at large plastic strains, texture evolution in complex strain paths and the initiation and growth of strain localisation events.

\section{CLASSIFICATION OF DAMAGE PROCESSES}

The problem of damage accumulation which has been explored most thoroughly is that of hole growth leading to ductile failure. A recent book by Thomason (4) gives a very clear and comprehensive view of this topic which can be considered as a sequence of events viz void nucleation, growth, and coalescence. The problem can be simplified and represented in the form of a map such as that shown in figure 1. In essence such maps contain two surfaces, a yield surface and a failure surface which may consist of several segments describing specific modes of failure. In addition they contain information on the rate of damage accumulation (represented by the dotted lines) and its dependence on hydrostatic pressure.

Such descriptions are of value in comparing fracture modes (5) and for the description of damage accumulation in uniform and dilute microstructures. However in composite materials other 
modes of damage can occur which represents important limits to the load bearing capacity of the material. An example is shown in figure 2 for an aligned $\mathrm{Al}-\mathrm{Ni}$ composite tested in compression. The process of damage accumulation and failure occurs by kinking (6). This buckling is not elastic in character but is a plastic buckling mode which occurs at a stress

$$
\sigma_{c}=\frac{\tau_{m}}{\Phi}
$$

where $\phi$ is the initial misalignment of the fibres and $\tau_{m}$ the shear yield stress of the matrix. The progress of the buckling process can be followed in terms of the scale and orientation of the damage region as shown in figure 3 .

At large strains cognizance must also be taken of localisation events such as failure at shear bands, or the accumulation of damage at the surface (7). Thus we can consider that in large strain operations the extent of plasticity may be limited by dilatent damage and fracture, local plastic buckling, localised shear or surface degradation. The occurrence of these processes will be a function of stress state, strain path, and temperature. In addition they may depend on microstructural features not only in the global sense of the average size and volume fraction but on the detailed spatial distribution or clustering of particles (12).

\section{BEHAVIOUR OF MODEL COMPONENTS AT LARGE PLASTIC STRAINS}

Model composites consisting of a polycrystalline copper matrix reinforced with continuous tungsten fibres were tested under a variety of deformation modes. The main characteristics of the composites are summarized in Table I and an example of the starting sample geometry and microstructure is shown in figure 4. In these samples the spacing and geometric arrangement of the tungsten fibres could be carefully controlled. A variety of mechanical tests have been performed on these samples including tension, plane strain compression and swaging and in the case of plane strain compression tests the experimental results have been compared with FEM simulation.

The results of tensile tests are shown in figure 5 for cases where the fibres were either parallel or perpendicular to the loading axis. The orientation of the fibres with respect to the tensile axis has a strong effect on the flow behaviour since this changes the efficiency of the load transfer process. When the fibres are parallel to the loading axis, the initial yield stress is elevated, the onset of damage occurs at very low strains (as evidenced by the drop in stress) and the overall ductility is low. For the case of $\mathrm{fibres}$ perpendicular to the loading axis, there is relatively little effect of the fibre arrangement on the yield stress and the initial work hardening rate. 
The local distribution of stress and strain in the composite can be followed using the finite element method calculations. The strain distribution results from FEM have been verified by experimental measurements of local strain (8). An example of the strain distribution for a sample with square arrangement of fibres is shown in figure 6. The consequences of the variaticns in local deformation can be clearly demonstrated by the pattern to subsequent recrystallization in these samples as shown in figure 7 .

An additional feature of the pattern of flow in model composites deformed in plane strain is the build up of tensile stresses in the $W$ fibres. These eventually result in cracking of the embedded fibres as shown in figure $8(\mathrm{a})$ and $8(\mathrm{~b})$. The location and orientation of the cracks in the fibres is dependent on the mode of testing as seen from a comparison of the tests in plane strain compression and uniaxial tension in figure $8(a)$ and (b).

In some cases the behaviour of the reinforcing phase may include complex changes of deformation path in the matrix. Figure 9 shows an example of a copper matrix reinforced with tungsten platelets and subjected to a plane strain compression of 0.2. The tungsten fibre has plastically yielded and subsequently a neck was formed in the platelet which is accompanied by the formation of shear bands in the matrix.

The behaviour of $\mathrm{Cu}-\mathrm{W}$ is well understood in terms of the load transfer process. For continuous fibre composites with the fibres parallel to the loading axis, the stress carried by the fibre is given by:

$$
\sigma_{\mathrm{fibre}}=V_{\mathrm{f}} \mathrm{E}_{\mathrm{f}} \varepsilon_{\mathrm{f}}
$$

For this case, Brockenbrough et al. (9) have shown that the geometric arrangement of fibres has little effect on the stress-strain behaviour. In contrast for transverse plane strain compression (Poole, 1993) or tension (Brockenbrough et al., 1991), a strong effect of particle arrangement on the stresses in the particle is observed at volume fractions above $25 \%$. This is also in good agreement with continuum plasticity arguments related to plastic constraints which were developed by Drucker (10).

The initiation of damage for these materials can be understood in terms of the critical tensile stress developed in the fibres. This is consistent with the experimental results for longitudinal tension, transverse tension, and transverse compression where damage initiation is observed by load drops in the stress-strain curve of the composite. The observation of fibre cracking at lower strains in transverse tension samples with square arrangements of fibres is also consistent with FEM calculations which predict higher stresses in the fibres for this geometry. 
The development of damage in tensile loading has been treated extensively in the literature (4) (5) (11). However if the prevailing stress state involves large hydrostatic pressure then as the faces of the crack are separated by plastic flow the matrix can extrude into the crack resulting in healing of the damage. This is illustrated in $f$ igure 10 and has been modelled by an elementary continuum solution by Brechet et al. (13) and could be modelled in detail by FEM methods. It should be noted here that the healing of damage refers to the geometric processes whereby the matrix is extruded into the crack it is not clear whether the interfaces created by this process are equivalent to these prior to any decohesion event.

For transverse tension samples, a different type of behaviour is observed. Upon failure of the fibre, the stress previously borne by the fibre is unloaded unto the adjacent fibres. This leads to a damage in the adjacent fibres followed by growth and finally coalescence of the voids. This process, and the high local plastic constraints may offer an explanation for the observation of damage initiation and growth in clustered regions in many composite materials (12).

\section{DAMAGE EVOLUTION IN PRACTICAL DEFORMATION PROCESSES}

A number of practical deformation processes can be simulated in the laboratory so that the complex strain history of an element can be followed together with metallographic studies strain localisation and damage evolution along this strain path.

An example of a deformation process of much commercial interest is ironing. This complex process can be simulated by a strip drawing process as shown in figure 11. A recent study by Heymes (14) has followed the deformation process both by studies of texture evolution and metallography. The study illustrates the complex relationships between damage due to particle cracking and strain localisation is heavily deformed Al alloys as shown in figure 12. In addition it has illustrated the importance of damage in particles close to the surface which interact with the die (figure 13). Decohesion of such particles may be involved in the complex interactions of the work piece and the die which occur in galling.

\section{CONCLUSIONS}

In the current work an attempt has been made to discuss the various ways in which damage accumulation can become the limiting feature of the load bearing capacity or the formability of a material. It is clear that this topic represents a valuable interaction between materials science and mechanics and encompasses topics such as damage mechanics and strain localisation. Valuable basic information can be obtained both from simple modelling approaches and from the use of model systems to quantify both damage initiation and evolution. Finally a variety of practical forming operations 
can be simulated to provide a direct input of studies of damage accumulation at large strains into the analysis and optimisation of forming operations both for conventional materials and new materials such as composites.

\section{ACKNOWLEDGEMENTS}

The author wishes to acknowledge the valuable contributions of his colleagues Warren Poole, Steve, Tao, Fabrice Heymes and Professors Yves Brechet and Robert Sowerby to the work which is contained in this paper. The financial support of NSERC (Canada) is also gratefully acknowledged.

\section{REFERENCES}

1) KACHANOV, L.M., Izv. Akad. Nauk SSSR Otd. Tekh $\underline{8}$, (1958), 26 .

2) LECKIE, F.A., Eng. Fract. Mech. 25, (1986), 505.

3) Lemaitre, L., Eng. Fract. Mech. 25, (1986), 523.

4) THOMASON, P.F., "Ductile Fracture of Metals", Pergamon Press (1990).

5) TEIRLINCK, D., ZOK, F., EMBURY, J.D. and ASHBY, M.F., Acta Met. $\underline{36},(1988), 1213$.

6) TAO, S. and EMBURY, J.D., Met. Trans. 24A, (1993), 713.

7) EMBURY, J.D. in "Formability and Metallurgical Structure" edited by A.K. SACHDEV, published by The Metallurgical Society $(1988), 101$.

8) POOLE, W.J., Ph.D. thesis, McMaster University, (1993).

9) BROCKENBROUGH, J.R., SURESH, S. and WEINECKE, H.A., Acta Met. 38, (1991), 735 .

10) DRUCKER, D.C., "High Strength Materials", edited by V. Zackay, J. Wiley, New York (1965), 795.

11) ARGON, A.S., IM, J. and SAFOGLU, R., Met. Trans. 6A, $(1975), 825$.

12) LLOYD, D.J., Acta Met. 39, (1991) 59.

13) BRECHET, Y., EMBURY, J.D., TAO, S. and NEWELL, J., Scripta Met. 28, (1993), 47 .

14) F. HEYMES, M.Eng. thesis, McMaster University (1992). 
Table I - Summary of Materials

\begin{tabular}{|l|l|l|l|l|}
\hline Material & Processing & $\begin{array}{l}\text { volume } \\
\text { fraction }\end{array}$ & $\begin{array}{l}\text { scale of } \\
\text { reinforce- } \\
\text { ment }\end{array}$ & $\begin{array}{l}\text { distribution of } \\
\text { reinforcement }\end{array}$ \\
\hline $\begin{array}{l}\text { Cu with } \\
\mathrm{W}_{\text {fibre }}\end{array}$ & $\begin{array}{l}\text { cast, deformed and } \\
\text { recrystallized } \\
\text { grain size of } 150 \\
\mu \mathrm{m}\end{array}$ & $20,30 \%$ & $\begin{array}{l}250-1000 \mu \mathrm{m} \\
\text { fibres }\end{array}$ & $\begin{array}{l}\text { triangular and } \\
\text { square } \\
\text { arrangements }\end{array}$ \\
\hline
\end{tabular}

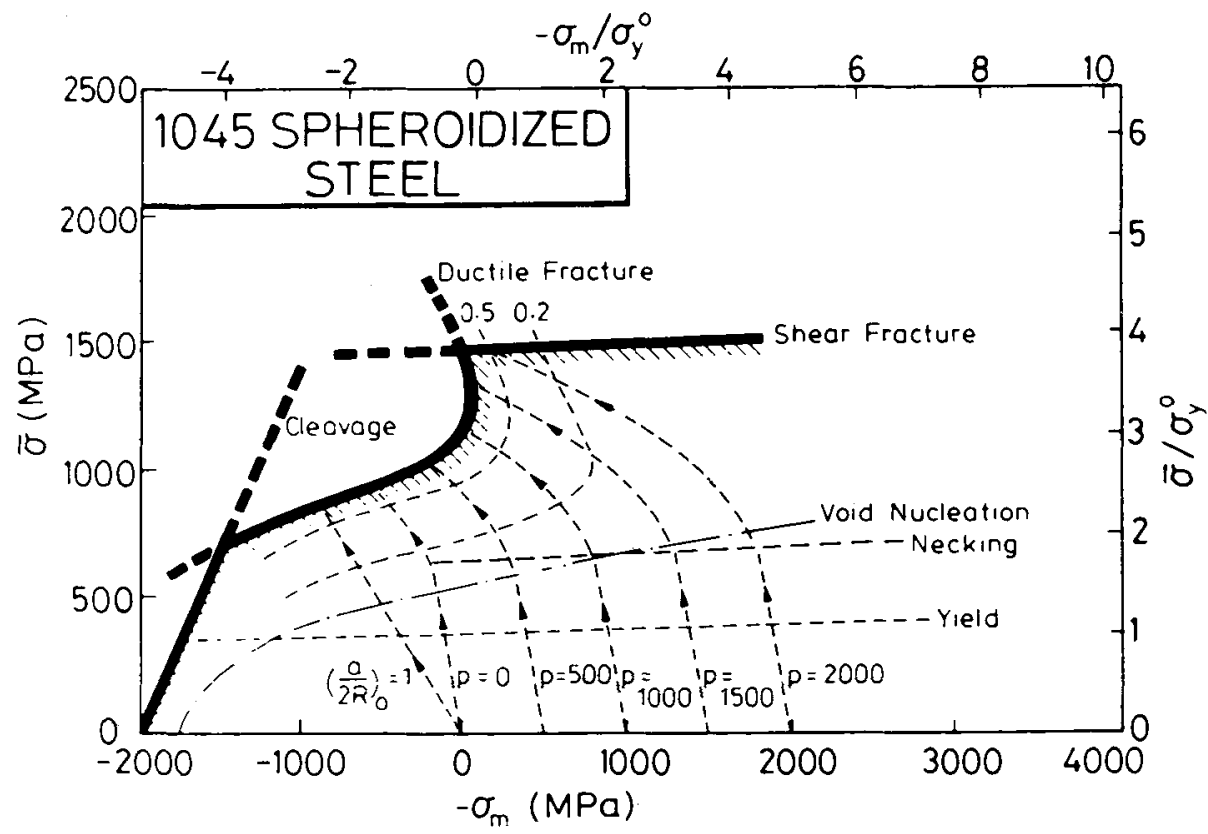

FIGURE 1. A schematic diagram showing the bounding fracture mechanisms observed in 1045 steel as a function of superimposed hydrostatic pressure. The 1 ines designated $0.2,0.5$ are contours of damage level. 


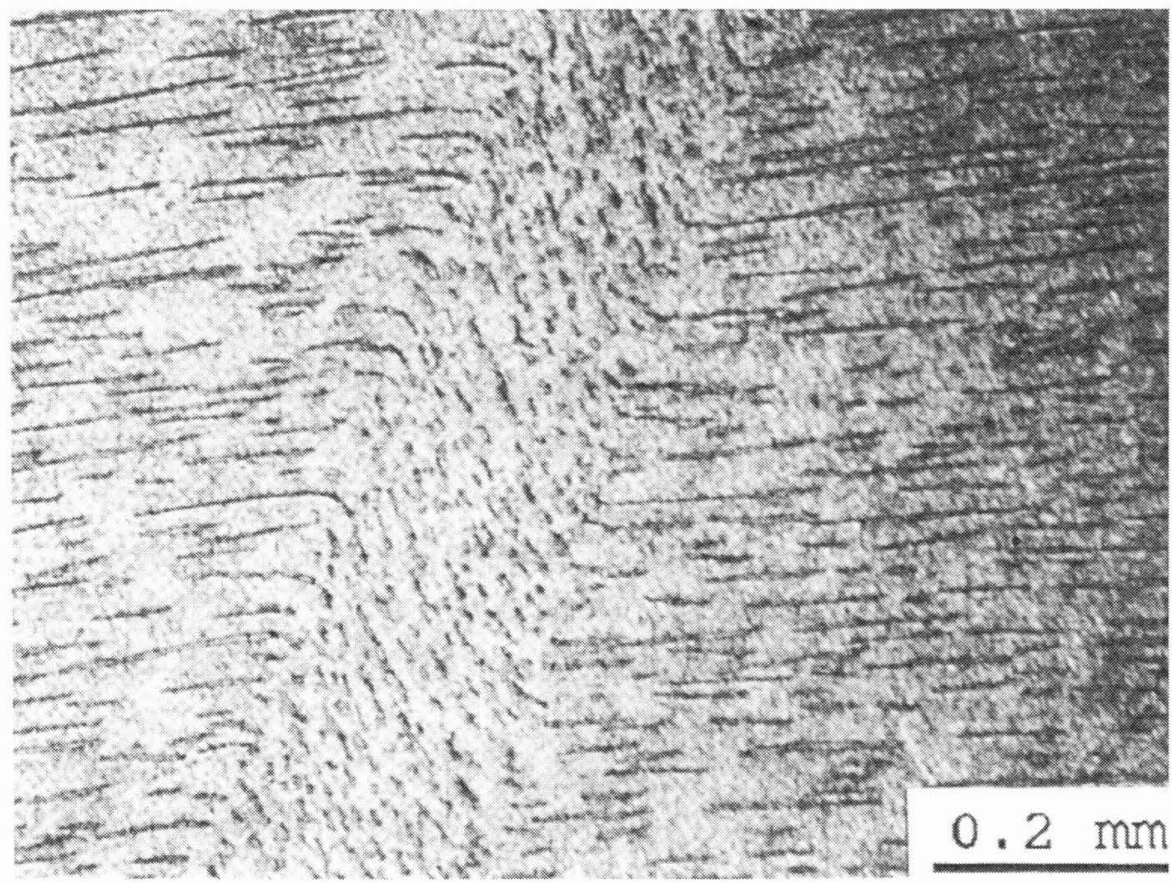

FIGURE 2. An optical micrograph showing kink band formations during compression of an aligned eutectic of Al-Ni.

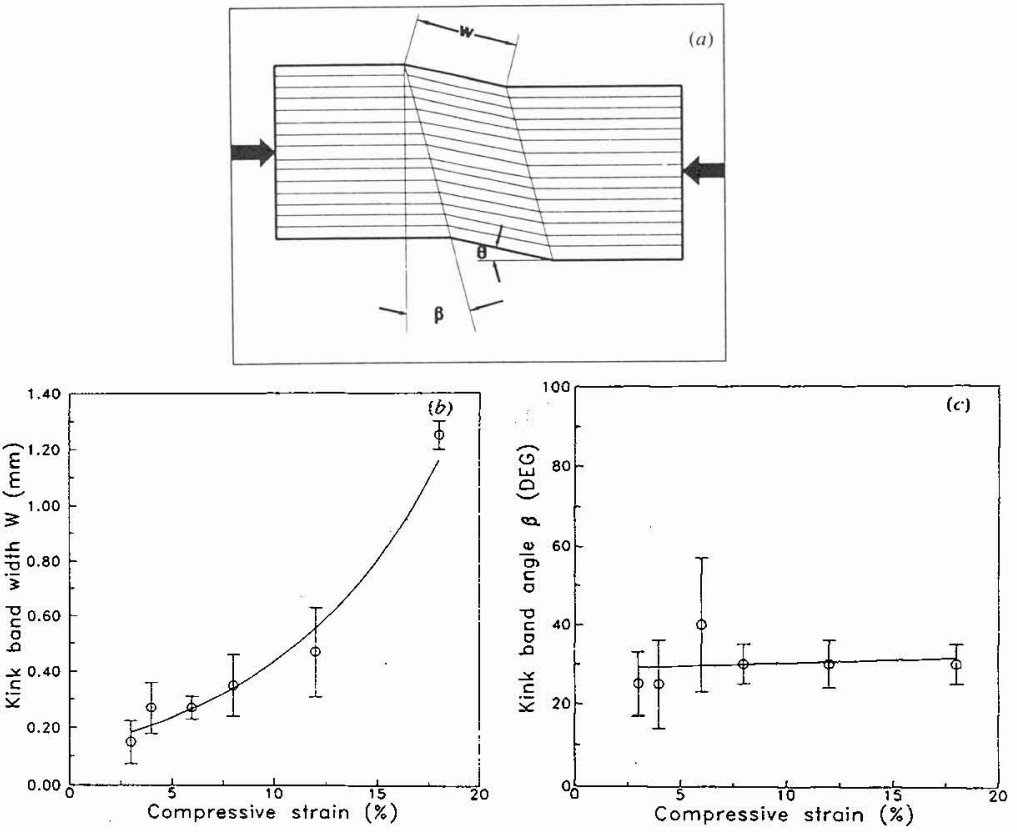

FIGURE 3. Diagrams showing the observed progression of kink bands with increasing imposed compression strain in aligned eutectics of $\mathrm{Al}-\mathrm{Ni}$. 

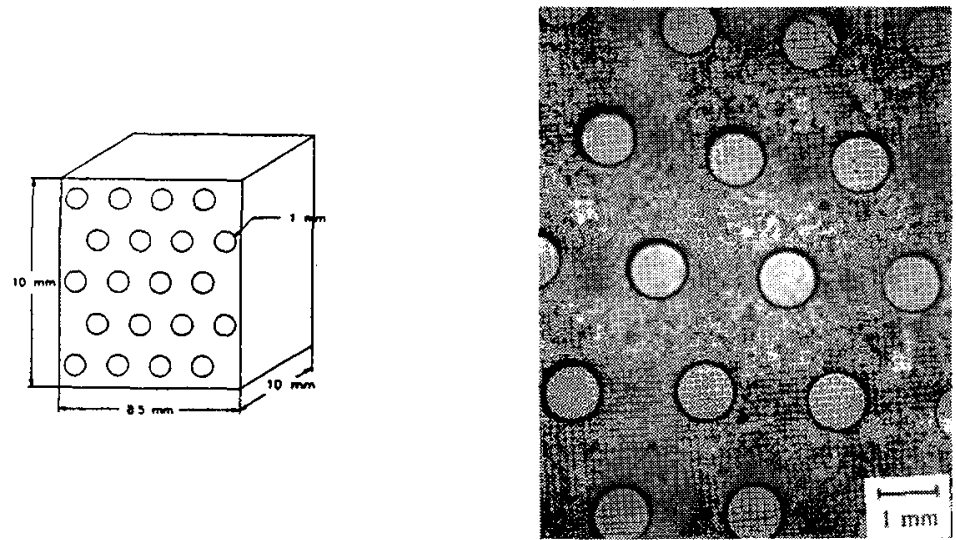

a)

b)

FIGURE 4. Copper-tungsten composites a) schematic of plane strain compression sample; b) initial microstructure.

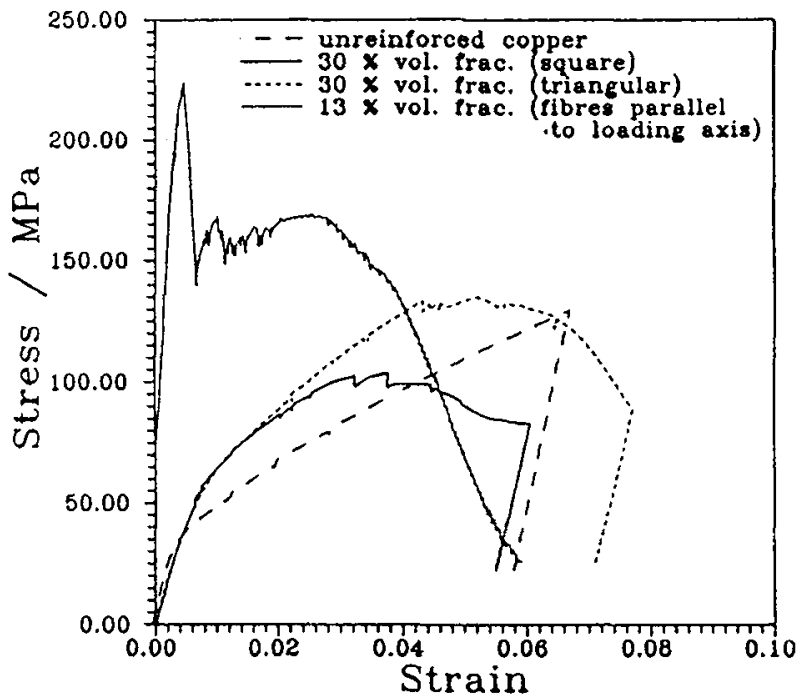

FIGURE 5. Stress strain curves for $\mathrm{Cu}-\mathrm{W}$ composites. The fibres are perpendicular to the loading axis except where noted. 


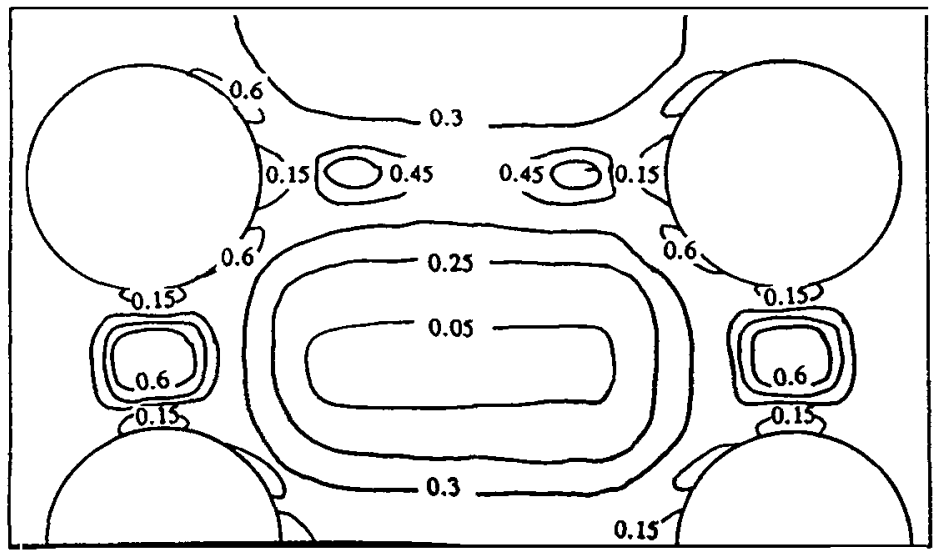

FIGURE 6. The strain distribution in a Cu-W composite with a square array of fibres.

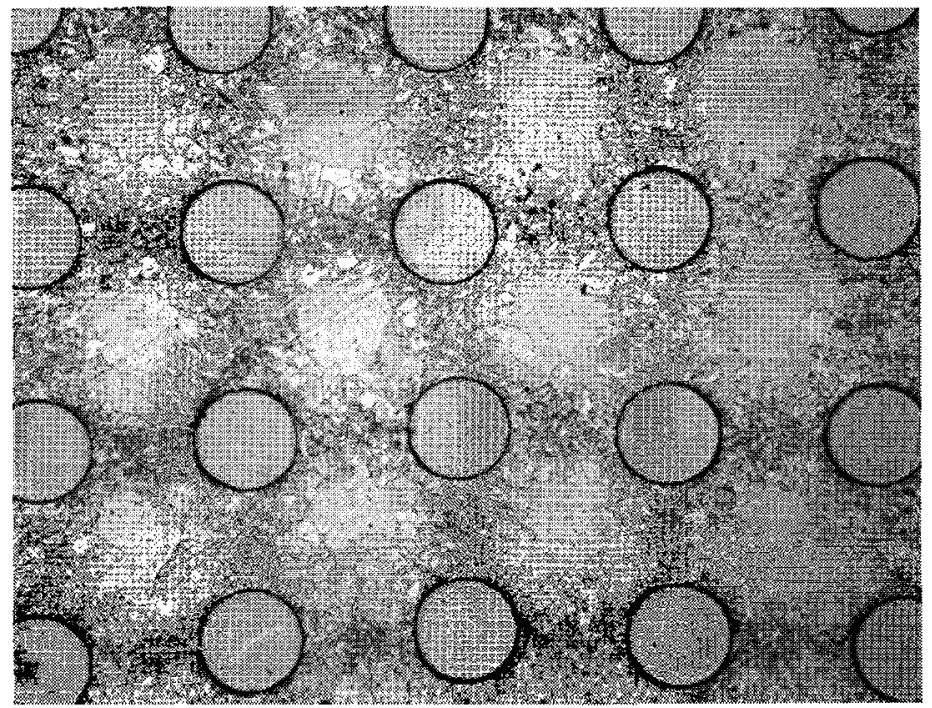

FIGURE 7. The pattern of subsequent recrystallization in a CuW composite with a square array of fibres. The recrystallization occurs in the regions of highest strain as shown in figure 6 . 


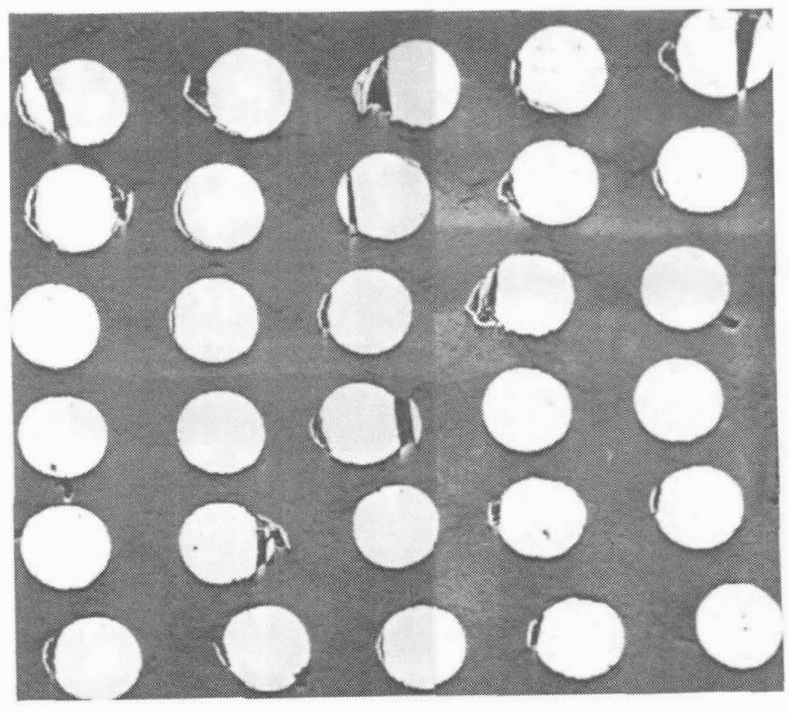

a)

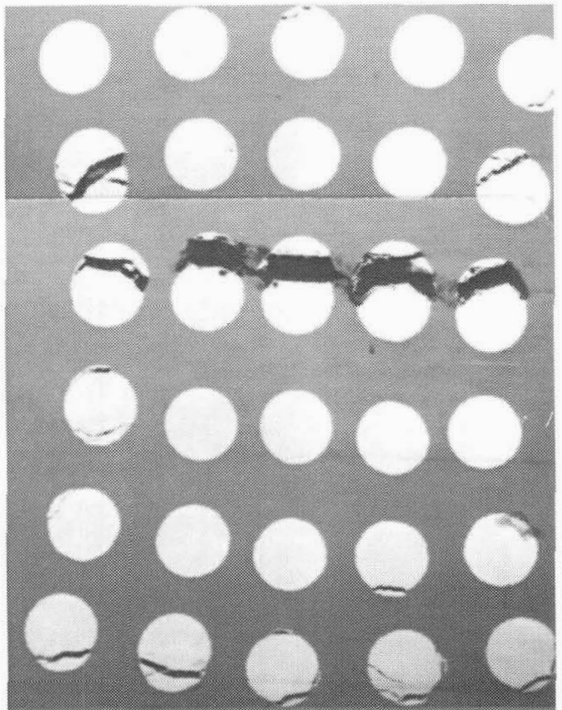

b)

FIGURE 8. The pattern of fibre fracture observed in the embedded $W$ fibres, when the axis of deformation is vertical. a) plane strain compression test, b) tensile test.

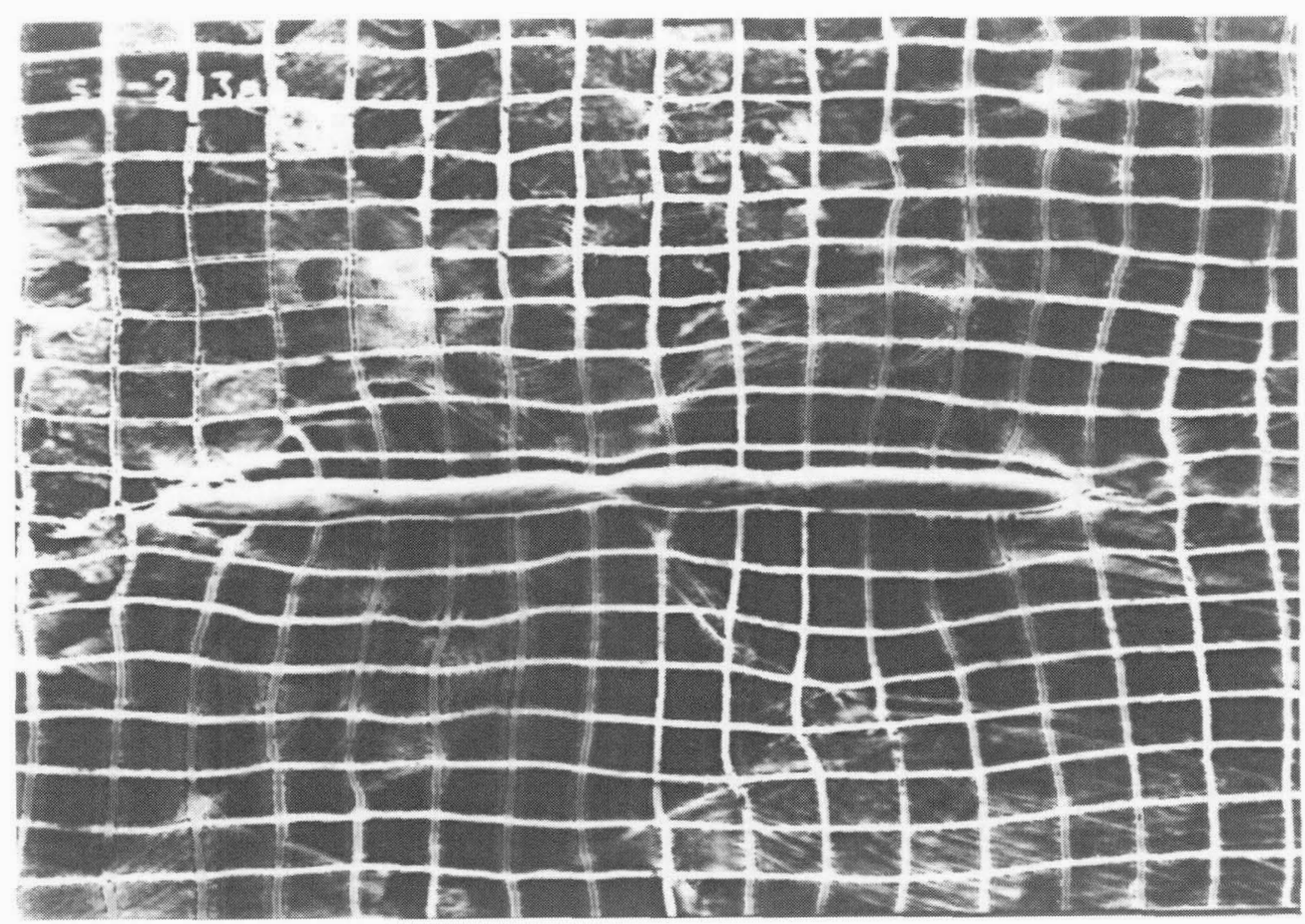

FIGURE 9. A micrography showing the relationship of local necking and shear band formation in a $\mathrm{Cu}-\mathrm{W}$ laminate. 


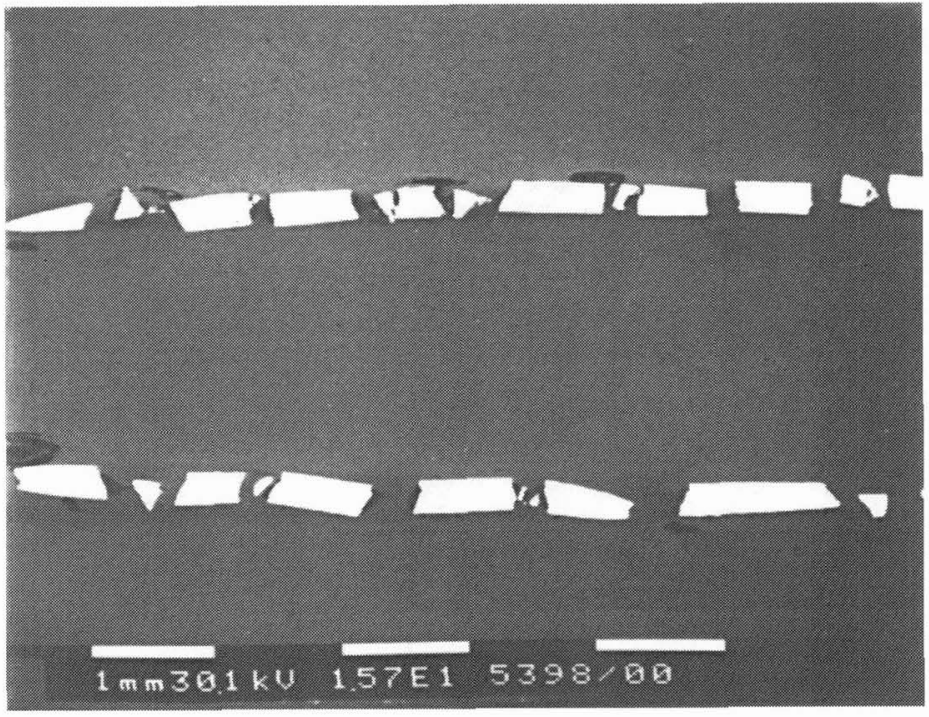

FIGURE 10. A micrography showing the extrusion of the matrix into, the voids in fractured fibres.

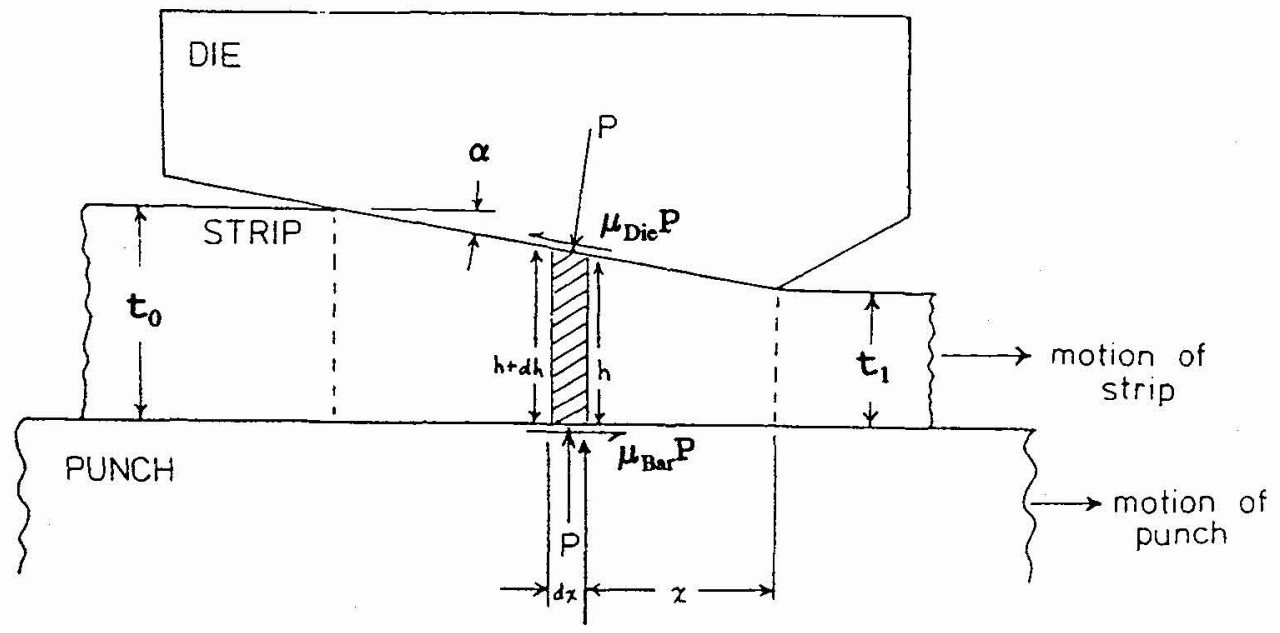

FIGURE 11. Schematic diagram of strip drawing deformation used to simulate ironing (ref. 14). 


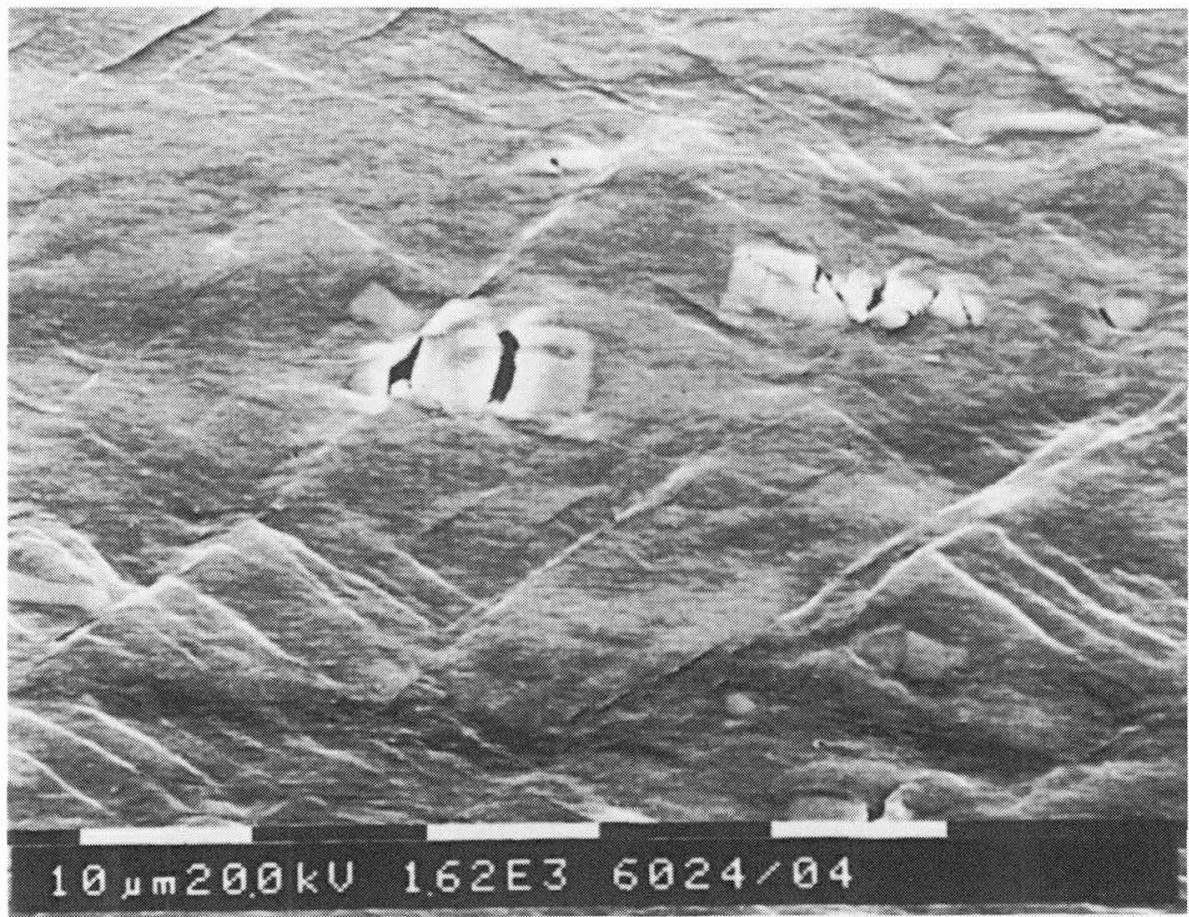

FIGURE 12. A micrograph showing the interaction between the pattern of shear banding and particle fracture in ironing.

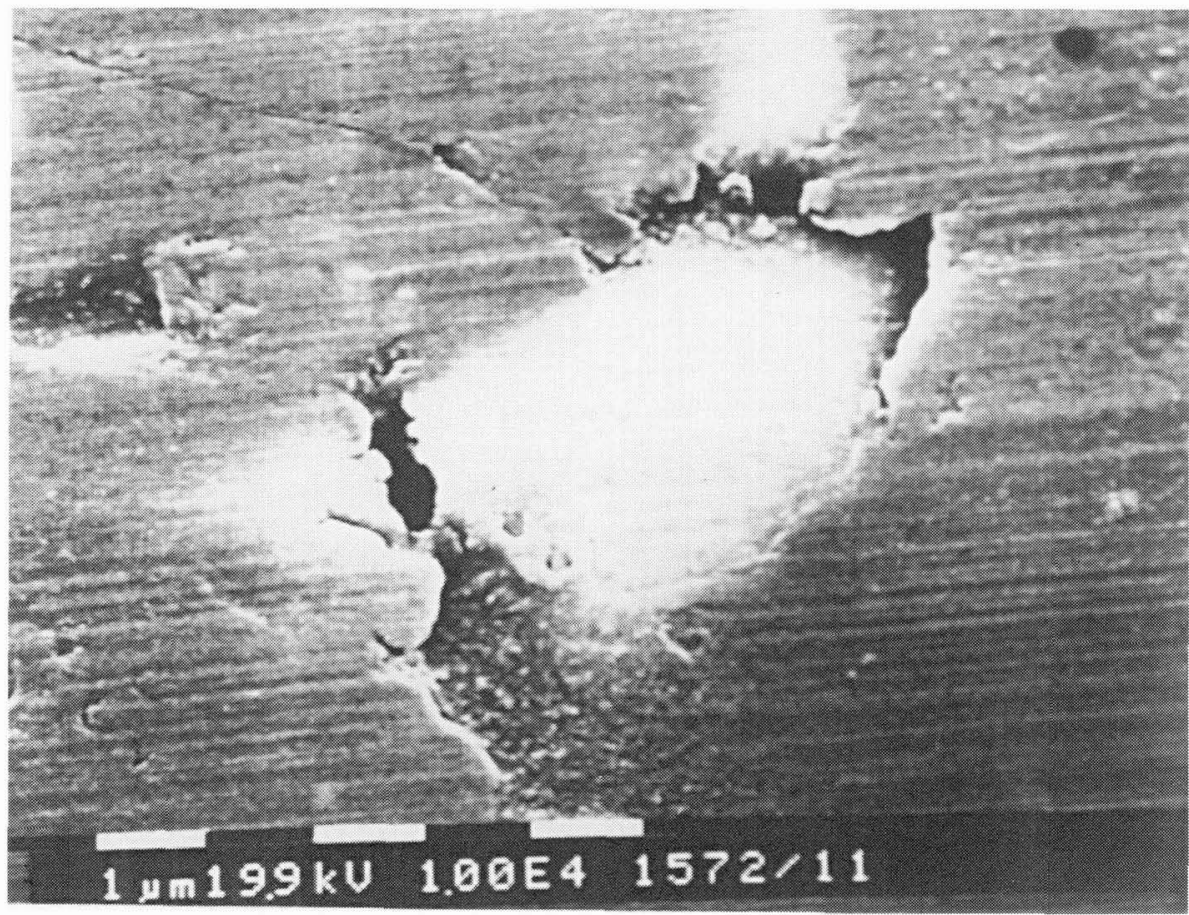

FIGURE 13. A micrograph showing particle fracture at the ironed surface which can lead to decoherence and galling. 